\title{
Protecting older patients with cardiovascular diseases from COVID-19 complications using current medications
}

\author{
Mariana Alves ${ }^{1} \cdot$ Marília Andreia Fernandes $^{2} \cdot$ Gülistan Bahat $^{3} \cdot$ Athanase Benetos $^{4} \cdot$ Hugo Clemente $^{5}$. \\ Tomasz Grodzicki ${ }^{6} \cdot$ Manuel Martínez-Sellés ${ }^{7}$. Francesco Mattace-Raso ${ }^{8} \cdot$ Chakravarthi Rajkumar $^{9} \cdot$ Andrea Ungar $^{10}$. \\ Nikos Werner ${ }^{11}$. Timo E. Strandberg ${ }^{12,13} \cdot$ EuGMS Special Interest Group inCardiovascular Medicine (Chairpersons \\ A. Ungar and A. Benetos)
}

Received: 20 February 2021 / Accepted: 15 April 2021 / Published online: 25 May 2021

(c) The Author(s) 2021

\section{Key summary points}

Aim To review current cardiovascular medications for benefits and potential harms duringCOVID-19.

Findings Several cardiovascular drugs have a potential to protect patients withCOVID-19, although evidence is largely based on observational studies and age-specific data arescarce.

Message Most current cardiovascular drugs can be safely continued during COVID-19, butgeneral conditions common in older patients must be considered.

\begin{abstract}
Purpose In the pathogenesis of severe COVID-19 complications, derangements of renin-angiotensin-aldosterone system (RAAS), vascular endothelial dysfunction leading to inflammation and coagulopathy, and arrhythmias play an important role. Therefore, it is worth considering the use of currently available drugs to protect COVID-19 patients with cardiovascular diseases.

Methods We review the current experience of conventional cardiovascular drugs [angiotensin-converting enzyme (ACE) inhibitors, angiotensin receptor blockers, anticoagulants, acetosalicylic acid, antiarrhythmic drugs, statins] as well as some
\end{abstract}

The members of EuGMS Special Interest Group in Cardiovascular Medicine are listed in acknowledgements.

Timo E. Strandberg

timo.strandberg@oulu.fi

1 Faculty of Medicine, Laboratory of Clinical Pharmacology and Therapeutics, Faculdade de Medicina, Serviço de Medicina III, Hospital Pulido Valente, CHULNUniversity of LisbonUniversidade de Lisboa, Lisbon, Portugal

2 Department of Internal Medicine, Hospital Curry Cabral, Centro Hospitalar Universitário de Lisboa Central, Lisbon, Portugal

3 Istanbul Medical School, Department of Internal Medicine, Division of Geriatrics, Istanbul University, Capa, 34093 Istanbul, Turkey

4 Department of Geriatrics and FHU CARTAGE-PROFILES, CHRU de Nancy and INSERM 1116, Université de Lorraine, Vandoeuvre-lès-Nancy, France

5 Department of Geriatrics, Centre Hospitalier de Wallonie Picarde, Tournai, Belgium

6 Department of Internal Medicine and Gerontology, Jagiellonian University Medical College, Cracow, Poland
7 Department of Cardiology, Hospital General Universitario Gregorio Marañón, CIBER-CV. Universidad Europea, Universidad Complutense, Madrid, Spain

8 Division of Geriatrics, Department of Internal Medicine, Erasmus MC University Medical Center, Rotterdam, The Netherlands

9 Brighton and Sussex Medical School, University of Sussex, Brighton, UK

10 Department of Geriatrics and Intensive Care Unit, University of Florence and Azienda Ospedaliero Universitaria Careggi, Firenze, Italy

11 Heart Center Trier, Krankenhaus der Barmherzigen Brüder, Trier, Germany

12 Helsinki University and Helsinki University Hospital, Haartmaninkatu 4, PO Box 340, N00029 Helsinki, Finland

13 University of Oulu, Center for Life Course Health Research, Oulu, Finland 
other drug classes (antidiabetic drugs, vitamin D and NSAIDs) frequently used by older patients with cardiovascular diseases. Data were sought from clinical databases for COVID-19 and appropriate key words. Conclusions and recommendations are based on a consensus among all authors.

Results Several cardiovascular drugs have a potential to protect patients with COVID-19, although evidence is largely based on retrospective, observational studies. Despite propensity score adjustments used in many analyses observational studies are not equivalent to randomised controlled trials (RCTs). Ongoing RCTs include treatment with antithrombotics, pulmonary vasodilators, RAAS-related drugs, and colchicine. RCTs in the acute phase of COVID-19 may not, however, recognise the benefits of long term anti-atherogenic therapies, such as statins.

Conclusions Most current cardiovascular drugs can be safely continued during COVID-19. Some drug classes may even be protective. Age-specific data are scarce, though, and conditions which are common in older patients (frailty, comorbidities, polypharmacy) must be individually considered for each drug group.

Keywords Antiarrhytmic $\cdot$ Anticoaculant $\cdot$ Aspirin $\cdot$ Colchicine $\cdot$ COVID-19 $\cdot$ Diabetes $\cdot$ NSAID $\cdot$ RAAS $\cdot$ Statin $\cdot$ Vitamin $\mathrm{D}$

\section{Background}

Ongoing SARS-CoV-2 (coronavirus) pandemic causing COVID-19 is potentially life threatening to older people with comorbidities. Males are more vulnerable than females, and patients with cardiometabolic diseases have higher risk for COVID-19-related severe complications and death. Complications are many, but cardiovascular and pulmonary ones are important and partly explain the susceptibility of patients with cardiovascular disease (CVD) to COVID-19 complications.

There is increasing knowledge of the potential benefits of steroids and specific antiviral treatments (e.g., remdesivir) in COVID-19 [1] and vaccination programs have commenced globally at end of 2020 . However, the outcome of viral infection does not hinge only on the specific effects of the invading pathogen, but it also depends on the host response and premorbid condition. Immune response of the host may be inappropriate, either too strong causing collateral damage (cytokine storm), or too weak due to ageing and diseases. Differences in immune function (both innate and adaptive) between males and females may explain sex differences in susceptibility to complications. Besides the immune function, other factors in the host factors are also important. Any infection is potentially more dangerous to a patient with CVD as compared to healthy individual, especially because of "endotheliitis" [2] predisposing to thrombotic and thromboembolic complications.

Hence, it is worthwhile considering using currently available cardiovascular drugs to improve prognosis in COVID-19 patients with CVD. In the pathogenesis of severe COVID-19 complications, vascular endothelial dysfunction seems to play an important role as a root cause for coagulopathy, thrombosis, platelet activation and heightened inflammatory response [2]. Accordingly, risk of myocardial infarction, stroke, deep venous thrombosis and pulmonary embolism are increased, and geriatricians need to be aware of these complications. Because coronavirus uses angiotensin-converting enzyme 2 (ACE2) as its receptor, molecular mechanisms include derangements of renin-angiotensin-aldosterone system (RAAS) [3]. Several existing cardiovascular drugs and other drugs have beneficial effects on endothelial function/RAAS and on the sequalae of their dysfunction. This offers opportunities to improve prognosis by re-purposing these therapies.

At the moment evidence is collected from retrospective, observational studies, which despite propensity score adjustments used in many analyses are not equivalent to randomized controlled trials (RCTs). A recent analysis of trials registered on ClinicalTrials.gov revealed that only $7 \%$ $(n=114)$ of interventional clinical trials related to COVID19 plan to evaluate cardiovascular therapies, most of them in a single center and enrolling $<1000$ COVID-19 inpatients (88\% RCTs). Most common drug classes were antithrombotics, pulmonary vasodilators, RAAS-related drugs, and colchicine [4].

Although evidence from RCTs is generally considered as most powerful, an important caveat related to cardiovascular drugs must be mentioned. An RCT performed in the acute phase of COVID-19 will not necessarily recognise potential benefits of chronic use of cardiovascular drugs which prevent atherosclerosis and preserve endothelial function long term, e.g., statins started before COVID-19 event. Performing an RCT in this setting is extremely difficult, even impossible in practice. The situation may be different for cardiovascular drugs (e.g., antiarrhythmics, anticoagulants, antithrombotics, colchicine) causing acute benefits by their effects on inflammation, thrombosis and coagulation.

In the following we shall review available evidence of cardiovascular drug treatment, mostly from observational studies, and their relationship-benefits or harms-to COVID-19. Besides conventional cardiovascular drugs we also include a review of nonsteroidal anti-inflammatory drugs (NSAIDs, including colchicine), as well as vitamin 
$\mathrm{D}$, because observational studies have linked low serum 25-hydroxyvitamin D concentrations with increased CVD risk [5]. Geriatric aspects are discussed where feasible, but age-specific data are usually lacking.

Data were sought from clinical databases (PubMed, Embase, preprints in medXriv) using COVID-19 and specific key words for each drug class. Interpretations of data and recommendations were based on a consensus among all authors.

\section{Renin-angiotensin-aldosterone system (RAAS) inhibitors}

ACE2 is a receptor present in many tissues throughout the human body, with a remarkable expression in the lungs type II pneumocytes, and it is important in the control of antiatherosclerosis processes and blood pressure [6]. ACE2 is an aminopeptidase that converts Angiotensin (Ang) II into Ang [1-7]. Ang II exerts powerful vasoconstrictor, pro-fibrotic, and pro-inflammatory effects through AT1 receptors. In contrast, Ang [1-7] is a potent vasodilator, anti-apoptotic, and anti-proliferative agent through Mas receptors. SARS-CoV-2 uses the ACE2 as a cellular receptor to entry the host cells [7]. In particular, the spike protein of SARS-CoV-2 is processed by transmembrane protease-serine 2 (TMPRSS2) and favors the binding of the spike protein to ACE2 [8].

Angiotensin-converting enzyme inhibitors (ACEi) and angiotensin-receptor blockers (ARB) increase the ACE2 receptor [8]. This led to the hypothesis that these drugs could promote the inoculation of SARS-CoV-2 and potentially leading to a higher risk of infection and/or disease severity [9]. This hypothesis generated social concern among population and academics.

Due to the fragility of this harmful assumption many medical societies recommended not to withdraw ACEi and/ or ARB due to their proved benefits in many diseases, such as hypertension, heart failure, coronary heart disease, diabetes mellitus, cerebrovascular disease and chronic kidney disease [10-12] and advocate an individualised treatment based on age, clinical condition, and co-morbidities of each patient, weighing the benefits of an effective treatment against the risk of abrupt drug discontinuation [13]. Indeed, subsequent systematic reviews and a recent RCT [14] support this recommendation $[15,16]$. Moreover, the infusion of the soluble isoform of ACE2 is being studied as a decoy receptor for SARS-CoV-2 particles, reducing infectivity and conserving cardioprotective actions via Ang [1-8].

Focusing in hypertensive patients, pooled data showed a possible benefit on the severity of SARS-CoV-2 infection in patients on ACEi and/or ARB treatment [15-18]. Ssentongo et al. [18] reported a significant 35\% lower risk of
COVID-19 mortality (7 studies) among hypertensive hospitalised patients on ACEi/ARB.

Regarding SARS-CoV-2 infection no clear difference was found between ACEi and ARB [15]. The putative protective mechanism is still speculative, but hypothetically lung protection may be provided through the activation of angiotensin II-receptors type 2 and G protein coupled MAS receptors [19].

Thus, current evidence supports that ACEi and ARB are not harmful in COVID-19. The evidence to support a potential benefit in hypertensive subgroup is growing; however, it is still based on very low grade of certainty and the results of ongoing clinical trials are needed to clarify this hypothesis [20-22]. Due the broad and well-known benefits of these drugs in cardiovascular risk and blood pressure control, their prescription should anyhow be encouraged according to previously known clinical indications irrespective of age [23].

Other RAAS drugs such as renin inhibitors (aliskiren), mineralocorticoid receptor antagonists (spironolactone or eplerenone), or even sacubitril, a neprilysin inhibitor, are much less studied, but also much less prescribed [24]. Ongoing clinical trials [25] are needed to clarify this theoretical hypothesis of benefit regarding mineralocorticoid receptor antagonists, till there physicians should follow current recommendations for prescribing these drugs [26]. Sacubitril/ valsartan association has also been a target for theoretical advantages mainly due to potential anti-inflammatory effect; however, evidence is still lacking [27, 28].

\section{In conclusion}

ACEi and ARB have shown to be safe for COVID-19 patients and their prescription should be encouraged according to previously known clinical indications, also for older patients. Data on other RAAS agents and on geriatric population are scarce and based on low grade evidence.

\section{Statins}

Before COVID-19 era in a randomized placebo-controlled trial of unselected acute respiratory distress syndrome (ARDS) patients [Hydroxymethylglutaryl-CoA Reductase Inhibition with Simvastatin in Acute Lung Injury to Reduce Pulmonary Dysfunction-2 (HARP-2) Study], simvastatin started acutely was safe but did not affect prognosis [29]. This and the potential ACE2 stimulating effect of statins initially raised concerns about their effects in SARS-CoV-2 infection. However, later subgroup analyses of HARP-2 trial suggested that ARDS patients with hyperinflammatory response (one third of all) did benefit from simvastatin treatment [30] raising some hopes for benefits also in COVID-19. 
We now have cumulative evidence from at least 27 observational studies during COVID-19 pandemic ([31-57], Supplementary Table 1). In all but one study [41, 58] the mortality risk of patients using statins is unchanged or lower than that of nonusers of statins after adjustments. The largest analysis about COVID-19-related death is a nationwide analysis of people with diabetes in England [type 1 (T1DM), $n=264$ 390; type 2 (T2DM), $n=2,874$ 020] [31]. Statin treatment was associated with a significant $38 \%$ lower risk of death in type 2 diabetes, and nonsignificant $18 \%$ lower risk in type 1 diabetes. A meta-analysis of other serious complications (13 studies about death risk) has been recently published [59]. Patients in these studies have been usually upper middle-aged, average age being around 60 years. An analysis of frail Belgian nursing home residents (average age 86 years) suggested that statin intake was associated with milder clinical symptoms during COVID-19, although mortality decrease (49\%) was not significant [60].

Several explanations are possible and biological and clinical plausibility of benefits and various pleiotropic mechanisms have been recently reviewed $[61,62]$. In addition to their established anti-atherosclerotic, antithrombotic and anti-inflammatory effects, statins also have immunomodulatory effects which may reduce risk of cytokine storm. Furthermore, statins may prevent virus entry by lowering cholesterol content of membranes, and even have direct antiviral effects. The most probable explanation could be, however, that patients at risk of cardiovascular complications of COVID-19 are better protected when using a statin. Their vasculature is apparently more resilient because of atherosclerosis prevention. Statins are known to improve endothelial function, and many complications related to COVID-19 are due to endothelial dysfunction [2]. Outside COVID-19, men aged 80 and older using statins had similar prognosis as nonusers despite more frequent multimorbidity and higher mortality risk [63]. A very recent population-based study in Italy showed that statin treatment is beneficial also among oldest and frail individuals [64].

Because observational studies of statins have not been unequivocal, confirmation from RCTs has been called for [59]. However, if a potential benefit of statin treatment is due to long term, ongoing use, then trials randomising patients during acute COVID-19 will not identify this benefit. To prove long-term benefits would require RCTs which currently seem unrealistic to be executed.

\section{In conclusion}

Observational studies have shown that ongoing statin treatment is neutral, or even beneficial, for patients with COVID19. Average age of patients in these studies has been around 60 years, but totality of evidence of statins (vide supra) suggests that benefits are independent of age. Ongoing statin treatment should not be discontinued, but there is no evidence of benefit (nor harm) if statin is started during COVID-19. Possible interactions should be considered if COVID-19 is being treated with antiretroviral drugs.

\section{Acetylsalicylic acid (ASA, aspirin)}

Acetylsalicylic acid (ASA) has well known antithrombotic effects, and is routine treatment at low dose in the prevention of CVD. ASA has also an anti-inflammatory effect by modulating the overproduction of pro-inflammatory cytokines and chemokines. Eventually, ASA has also antiviral activity against DNA and RNA viruses, including human coronaviruses $[65,66]$. Therefore, the question arises whether this drug might present an efficient treatment in patients with COVID-19 and some recent studies have investigated this issue.

In a study including 314 COVID-19 patients, ASA was independently associated with decreased risk of mechanical ventilation, intensive care unit admission, and in-hospital mortality, whereas there were no differences in major bleedings between ASA users and non-users [67]. A large observational study which included hospitalised COVID19 patients, reported a significantly lower incidence of in-hospital death in patients who received intermediatecompared to prophylactic-dose anticoagulation, and, separately, in patients who received in-hospital ASA compared to those who received no antiplatelet therapy [68].Conversely, a recent meta-analysis has investigated the possible association of ASA use in reducing mortality in patients with COVID-19 [69]. This meta-analysis included only 3 studies with a total of 1,054 patients, mortality rates were not statistically different between ASA users (22.6\%) and non-users (18.3\%) suggesting no protective effect of ASA in COVID19 patients.

\section{In conclusion}

Micro- and macrovascular thrombotic events are among the hallmarks of COVID-19. The optimal management strategy to prevent thrombosis in critically-ill patients, younger and older, with COVID-19 remains unknown. A dedicated RCT is needed to assess the possible protective role of ASA in COVID-19 patients.

\section{Anticoagulants}

Hypercoagulopathy leading to thromboembolic events is common in older COVID-19 patients and critically ill COVID-19 patients have a hypercoagulable profile despite the therapeutic (curative, intermediate or full) anticoagulant 
doses given [70]. Two meta-analysis in hospitalised COVID19 found an estimated pooled incidence of venous thromboembolism (VTE) of $17 \%$ and $21 \%$, with higher rates with routine screening [71, 72]. VTE significantly increased the odds of mortality by as high as $74 \%$ [71]. Also, an elevated D-dimer level is a critical risk factor for the mortality of the SARS-CoV-2 infection [73]. Thus, several scientific societies provided recommendations about stratification of VTE risk in hospitalised COVID-19 patients and strongly advised prophylactic (low or preventive dose) antithrombotic treatment with low molecular weight heparin (LMWH), fondaparinux or unfractioned heparin, unless contraindicated. [74-76] Some of these recommendations consider the possibility of giving intermediate-dose LMWH in patients with multiple risk factors [72] and extended prophylaxis after discharge $[74,75]$. While waiting for trial evidence concerning all COVID-19 patients from proper RCTs, a recent paper recommends switching all patients already being treated with oral anticoagulants (both antivitamin $\mathrm{K}$ and direct oral anticoagulants) to parenteral heparin at therapeutic levels to avoid the risk of over- or under treatment. [77].

Evidence about the effects of anticoagulation in COVID19 patients is growing but still limited. A systematic review found a benefit of anticoagulants among hospitalised COVID-19 adults and suggested that therapeutic doses might be associated with better survival compared to prophylactic doses [78], while another systematic review showed a slight tendency towards a reduction in the mortality rate among mechanically ventilated patients with COVID-19 receiving therapeutic-dose anticoagulation [79]. However, only few of the included studies were of good quality and no information was provided regarding various age groups. A meta-analysis of hospitalised COVID-19 patients showed that anticoagulation in therapeutic dose was beneficial [80]. An analysis of 4389 hospitalised COVID-19 adults found that anticoagulation was associated with lower mortality and intubation, with a trend towards a higher benefit with therapeutic doses [81]. The mean age was only 65 years and was lower in patients without anticoagulation. Interestingly, in 26 autopsies, 11 had thromboembolic disease, not clinically suspected. Data in advanced ages are scarce. A small retrospective study in older COVID-19 patients with interstitial pneumonia suggested a benefit of direct oral anticoagulants [82].

Alternative potential benefits of heparin have been reported in patients with COVID-19, including direct SARSCoV-2 antiviral activity and anti-inflammatory properties. $[83,84]$. However, this is still an area of uncertainty and RCTs are ongoing to clarify the best antithrombotic strategies in COVID-19 [85]. The use of anticoagulants should be balanced against the risks of bleeding. Intracranial hemorrhage seems to be relatively uncommon among COVID-19 patients but is associated with a high mortality rate and is mainly seen in older patients [86].

\section{In conclusion}

Anticoagulants, particularly when used in therapeutic doses, not just prophylactic dosing, seem to be beneficial in hospitalised patients with COVID-19. However, data are based on little high-quality evidence and are particularly scarce in advanced age population and in patients without anticoagulant treatment before admission. Consequently, optimal antithrombotic therapy in older patients with COVID-19 is yet to be determined.

\section{Beta-blockers}

The use of beta-blockers in older patients with COVID-19 infection is not controversial, as studies published so far have suggested less risk associated with their use [87, 88]. At the same time, people with co-morbidities (heart failure, hypertension, diabetes, ischemic heart disease or atrial fibrillation) that are indications for the use of beta-blockers are at increased risk for severe complications, including death, during infection caused by the SARS- 2 virus. These two observations indicate that there is no recommendation for withdrawal of beta-blockers during COVID-19.

Moreover, there are suggestions about the beneficial effects of beta-blocking agents, which would result from the potential role of beta-blockade in inhibiting the inflammatory response [89]. Several studies have indicated the role of catecholamines and stimulation of beta receptors in promoting the inflammatory response, as the overall effect of $\beta 2$-adrenergic stimulation is an exacerbation of inflammation, promotion of $\mathrm{B}$ cell antibody production, and stimulation of dentritic cells and macrophages to secrete proinflammatory cytokines [89]. The multi-organ failure observed during cytokine storm can be partially linked to the activation of beta-receptors in many SARS-CoV-2 target organs such as lungs, heart, gastrointestinal tract, liver, vascular smooth muscle, and skeletal muscle. Moreover, $\beta 2$-adrenergic receptors are expressed by the cells of the immune system, including macrophages, dentritic cells, and $\mathrm{T}$ and $\mathrm{B}$ lymphocytes.

The following hypothesised mechanisms of potentially beneficial effects of beta-blockade in different phases of COVID-19 have been proposed [90]:

- reduction of the SARS-CoV-2 host cell entry.

- decrease in proinflammatory cytokines production and inhibit cytokine storm.

- potential benefit in septic shock and ARDS.

- reduction of the hypercoagulation state.

- improvement of oxygenation level by beta-blockers.

- potential reduction of mucus hypersecretion. 


\section{In conclusion}

Taking into account the results of observational studies betablockers should not be stopped during COVID-19, and this applies also to older patients. Whether or not the anti-inflammatory effect of beta-blockers plays any clinically important role in prevention or treatment of cytokine storm has to be confirmed in prospective research and RCTs.

\section{Antiarrhythmic drugs (other than beta-blockers)}

Arrhythmias are related to an increased morbidity and mortality in COVID-19, and their inpatient incidence is between $7.9 \%$ and $16.7 \%$, possibly increasing up to $44 \%$ in patients admitted to intensive care unit [91]. Antiarrhythmic drugs diversely affect ion channels [92], of which particularly those mediating the selective passage of $\mathrm{Ca}^{2+}$ across cell membranes, modulate virus life cycles and play an important role in virus-host interaction [93-95]. Hence, bearing in mind the mechanisms of action and considering pleiotropic effects of some antiarrhythmic drugs, as well as the viral life cycle, it is natural to postulate they could work as antiviral drugs and affect SARS-CoV-2 infection.

In a large population study to assess the protective effect of several drugs acquired at the pharmacies $<30$ days preceding diagnosis of severe COVID-19, flecainide was one of the drugs associated with significantly reduced risk of infection and hospitalisation [96]. On a bioinformatic level, propafenone revealed activity against the main protease of SARS-CoV-2 and influenced its virulence. Regardless these promising results, clinical studies are obligatory [97].

Amiodarone, used to control a wide range of atrial and ventricular arrhythmias, has been suggested as potential drug for prevention or treatment of COVID-19 [92, 98]. The ReCOVery-SIRIO, a multicenter study, aims to determine the role of amiodarone or verapamil, in hospitalised patients within the initial stage of COVID-19 [93, 95]. Dronedarone, a noniodinated and less lipophilic derivate developed to treat atrial fibrillation and flutter, has a better safety profile than amiodarone [92, 99].

$\mathrm{Ca}^{2+}$-channel blockers diltiazem and verapamil, applied in the prevention and treatment of supraventricular tachycardias [92], have been hypothesised to affect SARS-CoV-2 infection by inhibiting $\mathrm{Ca}^{2+}$ entry via L-type voltage-gated $\mathrm{Ca}^{2+}$ channels, with ensuing antiviral effects [93, 95].

Also digoxin, a cardiac glycoside used in the rate control of atrial fibrillation and flutter [92] has antiviral activity [100]. There is scarce research relating the remaining antiarrhythmic drugs, including ivabradine, a selective $\mathrm{I}(f)$ current inhibitor to COVID-19.

\section{In conclusion}

Use of antiarrhythmic drugs in COVID-19 should be similar to patients in other diseases [98, 101]. Dose adjustments may be needed in older patients, and with renal or hepatic impairment [92, 102]. Despite intriguing experimental data and hypotheses of antiviral effects, these drugs are not indicated as a prophylactic therapy of SARS-CoV-2 infection at the moment.

\section{Antidiabetic drugs}

Diabetes is one of the most important comorbidities related to the severity of SARS-CoV-2 infection [103] and often associated with CVD. Reported prevalence of diabetes among COVID-19 patients ranges from 5\% to as high as $58 \%$, depending on the patient and study criteria [104, 105].

Recommendations for diabetes treatment in COVID-19 advocate intensification of glycaemic control as a means of primary prevention for a severe illness and antidiabetic drugs should not be discontinued in the absence of specific contraindications [106]. Moreover, some antidiabetic drugs have shown pleiotropic activity added to the glycaemic control and may represent benefits to fight SARS-CoV-2 infection [103].Moreover, some antidiabetic drugs have shown pleiotropic activity added to the glycaemic control, particularly potential antiproliferative and immunomodulatory effects, and may represent benefits to fight SARS-CoV-2 infection [103].

\section{Metformin}

Metformin was related to a decreased risk of mortality in patients with chronic lower respiratory diseases [104]. Regarding COVID-19, observational studies have suggested that metformin use in hospitalised patients with T2DM is associated with reduced mortality [107]. In the CORONADO (Coronavirus SARS-CoV-2 and Diabetes Outcomes) multicenter study ( $n=1317)$, metformin use on admission (56.6\%) was associated with a $41 \%$ reduced 7 -day mortality risk [108]. A large US study showed that the reduction in mortality is gender-dependent: $24 \%$ for females and nonsignificant for males in propensity-matched model [109]. The associated benefits of metformin on mortality due to COVID-19 are not restricted to patients with severe disease or hospitalisation. A retrospective analysis in nursing homes demonstrated similar results, showing that residents taking metformin had a significantly reduced 30-day mortality from COVID-19 diagnosis compared to residents without antidiabetic drugs [110].

Regarding safety, metformin may induce lactic acidosis in cases of multi-organ dysfunction necessitating 
discontinuation of the drug $[111,112]$. However, it can be safely continued in stable patients with normal oral intake and do not have nausea and vomiting. Dosing adjustment or interruption should be performed according to renal function [103, 113-115].

\section{Thiazolidinediones}

Experimental studies suggest that pioglitazone may upregulate ACE2 in insulin-sensitive tissues and, although this effect in the lung is still uncertain, this supposed increase in ACE2 expression has raised some concerns about the use of this drug in patients with diabetes and COVID-19 [104, 115-117]. Moreover, thiazolidinediones seem to increase the risk of pneumonia when compared to sulfonylureas and, taking into consideration the risk of fluid retention, it could be judicious to withhold PPAR- $\gamma$ agonists in acutely ill patients $[104,115,116]$.

\section{Dipeptidyl peptidase-4 inhibitors (DPP-4i)}

There is no sustained evidence to determine the impact of DPP-4i on clinical outcomes related to COVID-19 [103, 104, 107, 108, 114, 118-120]. As DPP-4i exhibit an optimal safety profile, even in fragile people, they remain a valid therapeutic option for the management of patients with T2DM and COVID-19 who are stable and with satisfactory oral intake $[115,120]$. However, dose adjustments may be required according to renal function and more data are needed for recommendations in critically ill patients $[114$, $115]$.

\section{Glucagon-like peptide-1 receptor agonists (GLP-1 RAs)}

GLP-1 RAs have shown to be particularly effective in obese T2DM patients and are indicated for patients at high risk or established atherosclerotic CVD due to evidence of cardiovascular protective effects $[113,121]$. However, none of the studies have demonstrated clear influence on outcomes related to COVID-19, and there is lack of evidence regarding the safety of use of GLP-1 RA in critically ill patients. Their use should be carefully considered or discontinued in the most fragile patients $[114,115,121]$.

\section{Sodium-glucose co-transporter-2 inhibitors (SGLT2is)}

SGLT2is are highly effective in the treatment of diabetes and have been strongly associated with improved CVD outcomes [103, 113, 114]. A multicenter RCT ((Dapagliflozin in Respiratory Failure in Patients with COVID-19-DARE-19) is underway to investigate the role of dapagliflozin in reducing disease progression, complications and all-cause mortality in COVID-19 [122].

SGLT2is are associated with an increased risk of volume depletion and euglycemic ketoacidosis, which could be greater in the context of severe infections. Therefore, it is recommended to withhold them in hospitalised patients with COVID-19, and also in very unwell outpatients [106, 109, 113, 114, 116, 120, 122].

\section{Sulfonylureas}

The number of patients using sulfonylureas has been low in observational studies of COVID-19, probably due to adverse effects [107, 122]. Although sulfonylureas and glinides apparently do not directly affect SARS-CoV-2, it is recommended to withhold them in patients with compromised oral intake or severe illness, to avoid the risk of hypoglycemia [114-116, 123].

\section{Insulin}

Insulin is a safe choice under most circumstances, being the only therapy for people with T1DM and considered the first-line treatment in hyperglycaemic critically ill patients $[113,117]$.

Several studies have shown that insulin therapy was linked to poor prognosis in COVID-19 [107, 108, 110]. However, it is important to underline that the poorer outcomes are probably due to the fact that use of insulin reflects more advanced diabetes and patients who are often older and frailer. Indeed, insulin often remains the only drug to achieve glucose control in critically ill patients, particularly those in intensive care units, where other glucose lowering drugs must be discontinued [105]. Moreover, given the wide clinical spectrum of COVID-19 and potential to deteriorate rapidly, it is reasonable to consider early introduction of insulin on hospital admission [116]. Hypoglycaemia should be avoided as it is also related to unfavourable outcomes $[114,115]$.

\section{In conclusion}

Data linking diabetes and COVID-19 are growing but still limited, especially in older population. An optimal glycaemic control is crucial to improve prognosis in COVID-19 patients with diabetes and pharmacological treatment must be carefully managed to avoid serious adverse reactions, particularly in the most fragile patients. There is evidence of extrapancreatic pleiotropic effects for some antidiabetic drugs that can represent a potential benefit in the context of COVID-19, but these effects specifically in older patients are unknown. 


\section{Vitamin D}

Epidemiologic data suggest that the risk of infectious diseases is higher when 25-hydroxyvitamin D [25(OH) D] levels are $<20 \mathrm{ng} / \mathrm{mL}(50 \mathrm{nmol} / \mathrm{L})$ and risk decreases with higher concentrations [124]. In RCTs vitamin D supplementation of 10-25 $\mu \mathrm{g}$ (400-1000units) a day had a small protective effect against acute respiratory infections [125, 126]. COVID-19 severity and mortality rates are higher in older adults, African Americans, patients with diabetes, chronic lung disease, and CVD—all groups with low vitamin D levels. Ecological studies suggest that high latitudes and winter season-risk factors for low vitamin $\mathrm{D}$-are associated with higher mortality rates in COVID19 [125, 126]. Consequently, the fact that risk for vitamin D deficiency overlaps with factors associated with mortality from COVID-19 has stimulated studies on the role of vitamin D in COVID-19, especially from a therapy viewpoint.

Because epidemiologic associations may be explained by the "healthy user" effect [127] clinical studies are needed. These have revealed mixed findings between serum 25(OH)D levels and risk for COVID-19 [128], and clear support for causality remains undetermined [126].

The subsequent question is whether vitamin $\mathrm{D}$ replacement or treatment with higher pharmacological doses may have a beneficial effect on COVID-19 risk, and/or severity and mortality. There is a strong rationale to study these effects [127]. The ability of adequate vitamin D status to prevent mortality associated with COVID-19 has been suggested by an increasing number of observational studies [129-131]. An example is the recent, large analysis from UK Biobank $(n=8297)$, where habitual use of vitamin D supplements was significantly associated with an adjusted 34\% lower risk of COVID-19 [132]. Yet, there are also conflicting findings [124, 127, 130]. Regarding effect in treatment of COVID-19, a one small $(n=76)$, low quality RCT reported significantly reduced disease severity among patients given a high dose of vitamin D on admission [133]. Another small trial $(n=40)$ reported that patients with mild or asymptomatic COVID-19 and given high-dose vitamin D supplementation [1500 $\mu \mathrm{g}$ $(60,000$ units) daily for 7 days] more likely were negative at third week [134]. On the other hand, a single oral dose of $5000 \mu \mathrm{g}$ (200,000 units) of vitamin D3 did not influence length of stay among patients with severe COVID-19 [135].

Currently, several larger, placebo-controlled trials with vitamin $D$ are in progress [124, 127, 136, 137].

It is suggested that the effect of vitamin D is prominent when there is either extreme deficiency, or high therapeutic doses are used. Generally, vitamin D is safe, especially if the dose does not exceed the upper tolerable limit [129]. Suggested dosing of daily vitamin D varies:

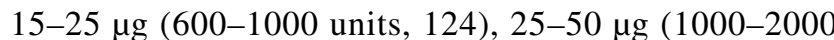
units, 129), or at daily equivalent doses of $25-100 \mu \mathrm{g}$ (1000-4000 units), daily or weekly [127]. In general, daily dosing is recommended-rather than higher doses weekly or monthly [124, 129]—and mega-doses are not recommended. As target level in serum, some authors suggest a level $>20 \mathrm{ng} / \mathrm{mL}$ (50 nmol/L) [129], many others set the target at $30 \mathrm{ng} / \mathrm{mL}(75 \mathrm{nmol} / \mathrm{L})[127]$. Nevertheless, one should consider that the beneficial effect is expected to be small and may take some time (months) to develop [129]. These conclusions may change by the newly emerging data.

Of note, the UK National Institute for Health and Care Excellence (NICE) COVID-19 rapid guideline: vitamin D (https://www.nice.org.uk/guidance/ng187) has been published very recently, indicating the validity of their existing advice that adults in the UK should take $10 \mu \mathrm{g}$ (400 units) of vitamin D daily between October and March, while certain populations at risk of vitamin D deficiency should consider taking vitamin $\mathrm{D}$ daily throughout the year.

\section{In conclusion}

The clinicians should consider the possibility of lowering the impact of COVID-19 by ensuring adequate vitamin $D$ replacement in populations, where vitamin D deficiency is prevalent. These often include older adults with CVD. Although the evidence of benefit in COVID-19 is largely observational, adequate vitamin $\mathrm{D}$ intake is nevertheless recommended for older persons to preserve bone health [138].

\section{Non-steroidal anti-inflammatory drugs (NSAIDs) including colchicine}

NSAIDs are widely used also by patients with CVD for pain, antipyretic effect, and management of inflammatory diseases. However, there have been concerns about the safety of NSAIDs use during COVID-19. It was speculated that ibuprofen can be detrimental when taken to treat general symptoms of a SARS-CoV-2 infection [139] However, on March 2020, the WHO released a statement after a literature review, that there is no evidence against the use of ibuprofen in COVID-19 patients [140] which was followed by confirmatory statements of FDA, EMEA, and others. These statements supported the continued use of NSAIDs for analgesia/antipyretic treatment and recommended continuation of regular therapy. The use of NSAIDs, such as ibuprofen, was not associated with severe COVID-19 or increased mortality in a Danish cohort study of 9236 patients [141]. Of them $248(2.7 \%)$ had presumably taken an NSAID in the 


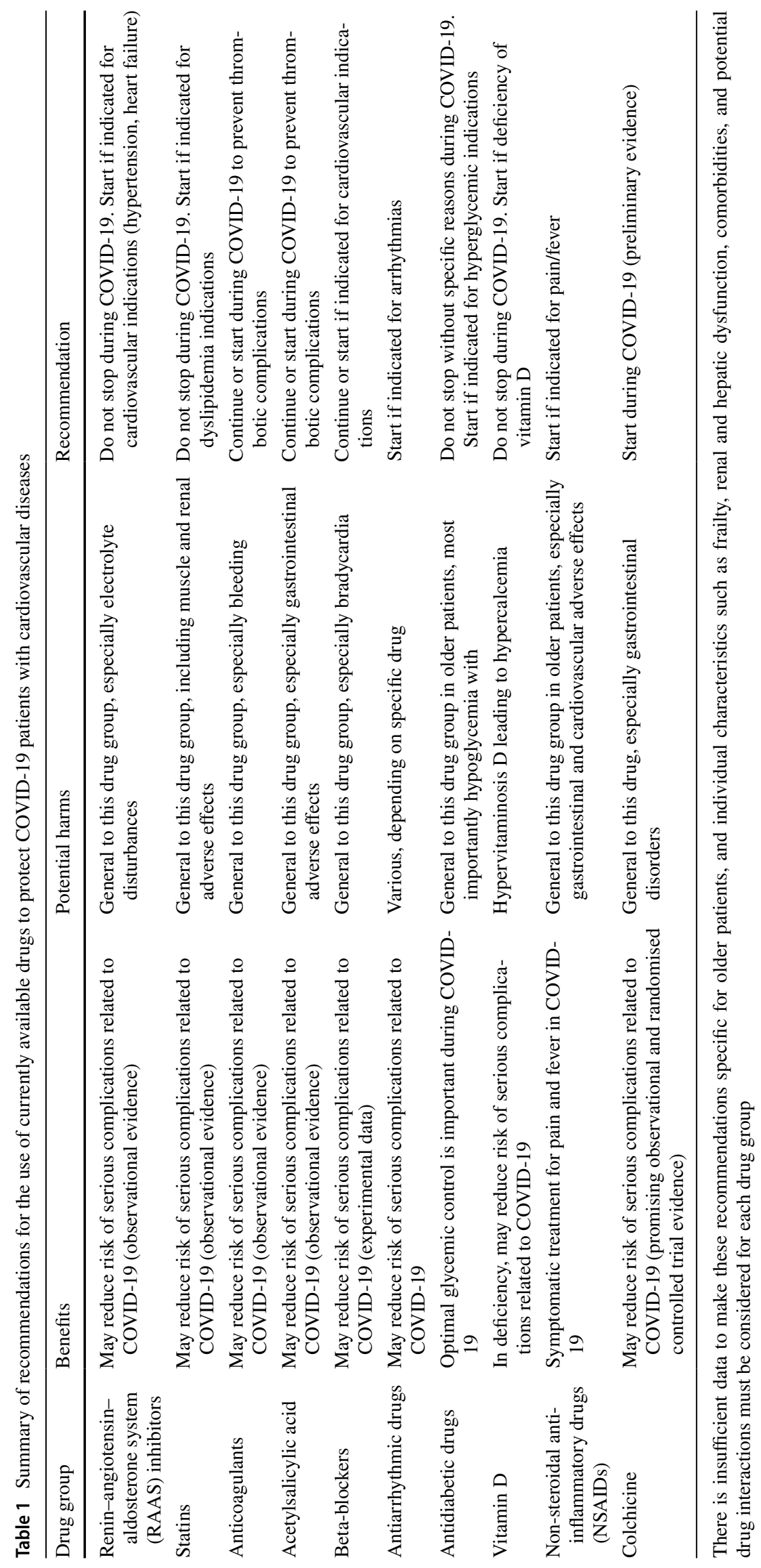


30 days before being positive diagnosed for SARS-CoV-2. There were no significant differences between NSAID users and non-users for 30 -day mortality ( $6.3 \%$ of vs. $6.1 \%$ ), hospitalisation (24.5\% vs. $21.2 \%$ ), or intensive care unit admission $(4.9 \%$ vs. $4.7 \%)$ [141]. An additional systematic review of NSAIDs in various respiratory infections including two RCTs gave inconclusive results mainly due to low quality of studies [142].

On the other hand, anti-viral and anti-inflammatory effects of NSAIDs could also be theoretically beneficial in COVID-19. Several in vitro and in vivo studies have evaluated NSAIDs in viral infections. The proposed mechanism of action, e.g., by indomethacin, is inhibition of intracellular viral RNA replication [143] and interference with virusmediated signal transduction pathways and transcription factors. As a clinical example, indomethacin $(25-50 \mathrm{mg}$ of twice daily) treatment in $>60$ non-hospitalised patients with suspected and confirmed COVID-19 was associated with symptomatic relief of incessant coughing and COVID19-associated general symptoms [144]. Besides anti-viral properties, NSAIDs may have anti-inflammatory properties, e.g., by attenuating cytokine storm in ARDS. However, data are limited and clinical evidence is lacking so far.

A highly intriguing new observation is the potential role of colchicine, an old anti-inflammatory drug used for gout and pericarditis, in COVID-19. Recent RCTs in patients with coronary artery disease have shown significant reduction of CVD events with colchicine treatment [145]. A metaanalysis of eight studies included 5778 COVID-19 patients and 2668 patients who received colchicine treatment [146]. Of the eight studies, three were RCTs, two and two retrospective and prospective cohort studies, respectively, and the remaining one was a case-control study. In the pooled analysis colchicine was associated with improvement in outcomes of COVID- 19 by $57 \%$, and a reduction of mortality also by $57 \%$. The reduction of outcomes was somewhat smaller (49\%) in RCTs than in observational studies (59\%), but still significant [146]. In January 2021, the Montreal Heart Institute announced that in the large, international COLCORONA clinical trial with non-hospitalised patients, colchicine, as compared to placebo, has reduced hospitalisations significantly by $25 \%$, the need for mechanical ventilation or deaths nonsignificantly by $50 \%$ and $44 \%$, respectively, among 4159 patients in whom the diagnosis of COVID-19 was proven by a naso-pharyngeal PCR test [147]. At the moment the data for COLCORONA are only available as a preprint.

\section{In conclusion}

Although there is no safety signal for detrimental effects of NSAID use in COVID-19, NSAID use need to be carefully evaluated in patients with CVD due to its association with kidney injury, and gastrointestinal complications, and increased risk of bleeding. This is especially important in older patients with COVID-19. Benefits and risks need to be individually evaluated. Currently, there is no evidence for initiation of NSAIDs as a specific therapeutic approach in COVID-19 patients. However, results from the meta-analysis and COLCORONA trial are apt to change this conclusion for colchicine.

\section{Overall conclusion}

Summary of the benefits and potential harms of various drug classes and recommendations for their use in COVID-19 is presented in Table 1. While these recommendations are independent of patients' age, drug-specific cautions due to frailty, renal or hepatic insufficiency, and potential comorbidities, contraindications, and drug interactions should be individually considered for all drug groups.

Supplementary Information The online version contains supplementary material available at https://doi.org/10.1007/s41999-021-00504-5.

Acknowledgements All authors are members of the EuGMS Special Interest Group of cardiovascular medicine. Dr. Grodzicki reports speaker's or consultation fees from Abbott, Sanofi, Servier, Pfizer, Boehringer-Ingelheim, and Abbott. Dr. Strandberg reports various cooperation (research, educational, consultative) with several companies (including Amgen, Novartis, Orion, Sankyo, Sanofi) marketing cardiovascular drugs.

Funding Open access funding provided by University of Helsinki including Helsinki University Central Hospital.

\section{Declarations}

Conflict of interest Other authors report no further conflicts of interest related to this paper.

Ethical approval Not applicable.

Informed consent Not applicable.

Open Access This article is licensed under a Creative Commons Attribution 4.0 International License, which permits use, sharing, adaptation, distribution and reproduction in any medium or format, as long as you give appropriate credit to the original author(s) and the source, provide a link to the Creative Commons licence, and indicate if changes were made. The images or other third party material in this article are included in the article's Creative Commons licence, unless indicated otherwise in a credit line to the material. If material is not included in the article's Creative Commons licence and your intended use is not permitted by statutory regulation or exceeds the permitted use, you will need to obtain permission directly from the copyright holder. To view a copy of this licence, visit http://creativecommons.org/licenses/by/4.0/. 


\section{References}

1. Kheirabadi D, Haddad F, Mousavi-Roknabadi RS, Rezaeisadrabadi M, Dehghan H, Fazlzadeh A (2021) A complementary critical appraisal on systematic reviews regarding the most efficient therapeutic strategies for the current COVID-19 (SARS-CoV-2) pandemic. J Med Virol. https://doi.org/10.1002/jmv.26811

2. Libby P, Lüscher T (2020) COVID-19 is, in the end, an endothelial disease. Eur Heart J 41:3038-3044

3. Varshney AS, Wang DE, Bhatt AS et al (2021) Characteristics of clinical trials evaluating cardiovascular therapies for Coronavirus disease 2019 registered on ClinicalTrials.gov: a cross sectional analysis. Am Heart 232:105-115. https://doi.org/10.1016/j.ahj. 2020.10.065

4. Monteonofrio L, Florio MC, Al Ghatrif M, Lakatta EG, Capogrossi MC (2020) Aging- and gender-related modulation of RAAS: potential implications in COVID-19 disease. Vasc Biol 3(1):R1-R14. https://doi.org/10.1530/VB-20-0014 (eCollection 2021)

5. Michos ED, Cainzos-Achirica M, Heravi AS et al (2021) Vitamin D, calcium supplements, and implications for cardiovascular health: JACC focus seminar. J Am Coll Cardiol 2(77):437-449. https://doi.org/10.1016/j.jacc.2020.09.617

6. Parsamanesh N, Pezeshgi A, Hemmati M, Jameshorani M, Saboory E (2020) Neurological manifestations of Coronavirus infections: role of angiotensin-converting enzyme 2 in COVID-19. Int J Neurosci. https://doi.org/10.1080/00207454. 2020.1849193

7. Hoffmann M, Kleine-Weber H, Schroeder S et al (2020) SARSCoV-2 cell entry depends on ACE2 and TMPRSS2 and is blocked by a clinically proven protease inhibitor. Cell 181(271280):e8. https://doi.org/10.1016/j.cell.2020.02.052

8. Nishiga M, Wang DW, Han Y, Lewis DB, Wu JC (2020) COVID19 and cardiovascular disease: from basic mechanisms to clinical perspectives. Nat Rev Cardiol 17:543-558. https://doi.org/10. 1038/s41569-020-0413-9

9. Fang L, Karakiulakis G, Roth M (2020) Are patients with hypertension and diabetes mellitus at increased risk for COVID-19 infection? Lancet Respir Med 8(4):e21. https://doi.org/10.1016/ S2213-2600(20)30116-8

10. de Simone G. Position statement of the ESC council on hypertension on ACE-inhibitors and angiotensin receptor blockers. https://www.escardio.org/Councils/Council-on-Hypertension(CHT)/News/position-statement-of-the-esc-council-on-hyper tension-on-ace-inhibitors-and-ang. Accessed 2 Dec 2020

11. The Renal Association, UK position statement on COVID-19 and ACE inhibitor/angiotensin receptor blocker use. https://renal.org/ health-professionals/covid-19/ra-resources/renal-association-ukposition-statement-covid-19-and-ace

12. Rodrigues CIS (2020) Position paper of the department of hypertension of the Brazilian Society of Nephrology: use of renin-angiotensin system blockers during the course of Covid19 infection. J Bras Nefrol 42:47-48. https://doi.org/10.1590/ 2175-8239-JBN-2020-S112

13. Sieńko J, Kotowski M, Bogacz A et al (2020) COVID-19: the influence of ACE genotype and ACE-I and ARBs on the course of SARS-CoV-2 infection in elderly patients. Clin Interv Aging 15:1231-1240. https://doi.org/10.2147/CIA.S261516

14. Lopes RD, Macedo AVS, de Barros E, Silva PGM et al (2021) Effect of discontinuing vs continuing angiotensin-converting enzyme inhibitors and angiotensin II receptor blockers on days alive and out of the hospital in patients admitted with COVID-19: a randomized clinical trial. JAMA 325:254-264

15. Ren L, Yu S, Xu W, Overton JL, Chiamvimonvat N, Thai PN (2020) Lack of association of antihypertensive drugs with the risk and severity of COVID-19: a meta-analysis. J Cardiol. https://doi.org/10.1016/j.jjcc.2020.10.015

16. Caldeira D, Alves M, Gouveia E, Melo R et al (2020) Angiotensin-converting enzyme inhibitors and angiotensin-receptor blockers and the risk of COVID-19 infection or severe disease: systematic review and meta-analysis. Int J Cardiol Hear Vasc 31:100627. https://doi.org/10.1016/j.ijcha.2020.100627

17. Barochiner J, Martínez R (2020) Use of inhibitors of the reninangiotensin system in hypertensive patients and COVID-19 severity: a systematic review and meta-analysis. J Clin Pharm Ther 45:1244-1252. https://doi.org/10.1111/jcpt.13246

18. Ssentongo AE, Ssentongo P, Heilbrunn ES et al (2020) Reninangiotensin-aldosterone system inhibitors and the risk of mortality in patients with hypertension hospitalised for COVID-19: systematic review and meta-analysis. Open Heart 7(2):1353. https://doi.org/10.1136/openhrt-2020-001353

19. Namsolleck P, Moll GN (2020) Does activation of the protective renin-angiotensin system have therapeutic potential in COVID19? Mol Med. https://doi.org/10.1186/s10020-020-00211-0

20. ClinicalTrials.gov. Coronavirus (COVID-19) ACEi/ARB investigation (CORONACION). https://clinicaltrials.gov/ct2/show/ NCT04330300. Accessed 12 Dec 2020

21. ClinicalTrials.gov. Elimination or prolongation of ACE inhibitors and ARB in Coronavirus disease 2019 (REPLACECOVID). https://clinicaltrials.gov/ct2/show/NCT04338009. Accessed 12 Dec 2020

22. ClinicalTrials.gov. Stopping ACE-inhibitors in COVID-19 (ACEI-COVID). https://clinicaltrials.gov/ct2/show/NCT04 353596. Accessed 12 Dec 2020

23. Williams B, Mancia G, Spiering W et al (2018) 2018 ESC/ ESH guidelines for the management of arterial hypertension: the task force for the management of arterial hypertension of the European society of cardiology (ESC) and the European society of hypertension (ESH). Eur Heart J 39:3021-3104. https://doi.org/10.1093/eurheartj/ehy339

24. de Abajo FJ, Rodríguez-Martín S, Lerma V et al (2020) Use of renin-angiotensin-aldosterone system inhibitors and risk of COVID-19 requiring admission to hospital: a case-population study. Lancet 395:1705-1714. https://doi.org/10.1016/S01406736(20)31030-8

25. Mareev VY, Orlova YA, Pavlikova EP, Matskeplishvili ST, Akopyan ZA, Plisyk AG (2020) Combination therapy at an early stage of the novel coronavirus infection (COVID-19). Case series and design of the clinical trial "BromhexIne and Spironolactone for Coronavirus Infection requiring hospitalization (BISCUIT).” Kardiologiya 60:4-15. https://doi.org/10. 18087/cardio.2020.8.n1307

26. Ponikowski P, Voors AA, Anker SD et al (2016) 2016 ESC guidelines for the diagnosis and treatment of acute and chronic heart failure. Eur Heart J 37:2129-2200m. https://doi.org/10. 1093/eurheartj/ehw 128

27. Bellis A, Mauro C, Barbato E, Trimarco B, Morisco C (2020) The rationale for angiotensin receptor neprilysin inhibitors in a multi-targeted therapeutic approach to COVID-19. Int J Mol Sci. https://doi.org/10.3390/ijms21228612

28. Acanfora D, Ciccone MM, Scicchitano P, Acanfora C, Casucci G (2020) Neprilysin inhibitor-angiotensin II receptor blocker combination (sacubitril/valsartan): rationale for adoption in SARS-CoV-2 patients. Eur Hear J-Cardiovasc Pharmacother 6:135-136. https://doi.org/10.1093/ehjcvp/pvaa028

29. McAuley DF, Laffey JG, O'Kane CM et al (2014) Simvastatin in the acute respiratory distress syndrome. N Engl J Med 371:1695-1703

30. Caffee CS, Delucchi KL, Sinha P et al (2018) ARDS subphenotypes and differential response to simvastatin: secondary 
analysis of a randomized controlled trial. Lancet Respir Med 6:691-698

31. Holman N, Knighton P, Kar P, O'Keefe J, Curley M, Weaver A (2020) Risk factors for COVID-19-related mortality in people with type 1 and type 2 diabetes in England: a population-based cohort study. Lancet Diabetes Endocrinol 8:823-833

32. Mallow PJ, Belk KW, Topmiller M, Hooker EA (2020) Outcomes of hospitalized COVID-19 patients by risk factors: results from a United States hospital claims database. J Health Econ Outcomes Res 7:165-174

33. Lee HY, Ahn J, Park J et al (2021) Beneficial effect of statins in COVID-19-related outcomes-brief report a national population-based cohort study. Arterioscler Thromb Vasc Biol 41:e175-e182. https://doi.org/10.1161/ATVBAHA.120. 315551

34. Butt JH, Gerds TA, Schou M, Kragholm K, Phelps H-B (2020) Association between statin use and outcomes in patients with coronavirus disease 2019 (COVID-19): a nationwide cohort study. BMJ Open 2020:10

35. Zhang XJ, Qin JJ, Cheng X, Shen L, Zhao YC, Yuan Y (2020) In-hospital use of statins is associated with a reduced risk of mortality among individuals with COVID-19. Cell Metab 32(176-87):e4

36. Saeed O, Castagna F, Agalliu I, Xue X, Patel SR, Rochlani Y (2020) Statin use and in-hospital mortality in diabetics with COVID-19. J Am Heart Assoc 9:e018475

37. Grasselli G, Greco M, Zanella A, Albano G, Antonelli M, Bellani G (2020) Risk factors associated with mortality among patients with COVID-19 in intensive care units in Lombardy. Italy JAMA Intern Med 180:1345-1355

38. Torres-Pena JD, Perez-Belmonte LM, Fuentes-Jimenez F et al (2021) Prior treatment with statins is associated with improved outcomes of patients with COVID-19: data from the SEMI-COVID-19 Registry. Drugs. https://doi.org/10.1007/ s40265-021-01498-x

39. Gupta A, Madhavan MV, Poterucha TJ, DeFilippis EM, Hennessey JA, Redfors B (2020) Association between antecedent statin use and decreased mortality in hospitalized patients with COVID-19. Res Sq. https://doi.org/10.21203/rs.3.rs-56210/v1

40. Lala A, Johnson KW, Januzzi JL et al (2020) Prevalence and impact of myocardial injury in patients hospitalized with COVID-19 infection. J Amer Coll Cardiol. https://doi.org/10. 1016/j.jacc.2020.06.007

41. Cariou B, Goronflot T, Rimbert A, Boullu S, Le May C, Moulin P (2020) Routine use of statins and increased mortality related to COVID-19 in inpatients with type 2 diabetes: results from the CORONADO study. Diabetes Metab S1262-3636(20):3015330161. https://doi.org/10.1016/j.diabet.2020.10.001

42. Masana L, Correig E, Rodriguez-Borjabad C, Anoro E, Arroyo JA, Jerico C (2020) Effect of statin therapy on Sars-Cov-2 infection-related mortality in hospitalized patients. Eur Heart J Cardiovasc Pharmacother. https://doi.org/10.1093/ehjcvp/pvaa128

43. Fan Y, Guo T, Yan F et al (2020) Association of statin use with the in-hospital outcomes of 2019-coronavirus disease patients: a retrospective study. Front Med (Lausanne) 17(7):584870. https:// doi.org/10.3389/fmed.2020.584870

44. Yetmar ZA, Challener DW, Tleyjeh IM et al (2021) Association between chronic statin use and 30 day mortality in hospitalized patients with COVID-19. Mayo Clin Proc Innov Qual Outcomes. https://doi.org/10.1016/j.mayocpiqo.2021.02.002

45. Nicholson CJ, Wooster L, Sigurslid HH et al (2020) Estimating risk of mechanical ventilation and mortality among adult COVID-19 patients admitted to mass general Brigham: the VICE and DICE scores. medRxiv. https://doi.org/10.1101/2020.09.14. 20194670.Preprint
46. Lohia P, Kapur S, Benjaram S, Mir T (2021) Association between antecedent statin use and severe disease outcomes in COVID19: a retrospective study with propensity score matching. J Clin Lipidol S1933-2874(21):00053-00062. https://doi.org/10. 1016/j.jacl.2021.03.002

47. Aparisi A, Amat-Santos IJ, Otero DL, Marcos-Mangas M, Gonzalez-Juanatey JR, San Roman JA (2021) Impact of statins in patients with COVID-19. Rev Esp Cardiol. https://doi.org/10. 1016/j.recesp.2021.01.009

48. Tan WYT, Young BE, Chien Lye D, Chew DEK, Dalan R (2020) Statin use is associated with lower disease severity in COVID-19 infection. Sci Rep 10:17458

49. Bifulco M, Ciccarelli M, Bruzzese D, Dipasquale A, Lania AG, Mazziotti G (2020) The benefit of statins in SARS-CoV-2 patients: further metabolic and prospective clinical studies are needed. Endocrine 20:1-3. https://doi.org/10.1007/ s12020-020-02550-8

50. Alamdari NM, Afaghi S, Rahimi FS, Tarki FE, Tavana S, Zali A (2020) Mortality risk factors among hospitalized COVID-19 patients in a major referral center in Iran. Tohoku J Exp Med 252:73-84

51. Chacko SR, DeJoy R 3rd, Lo KB et al (2021) Association of pre-admission statin use with reduced in-hospital mortality in COVID-19. Am J Med Sci S0002-9629(21):00089-00096. https://doi.org/10.1016/j.amjms.2021.03.001

52. Soleimani A, Kazemian S, Karbalai SS, Aminorroaya A, Shajari Z, Hadadi A (2020) Effects of angiotensin receptor blockers (ARBs) on in-hospital outcomes of patients with hypertension and confirmed or clinically suspected COVID-19. Am J Hypertens. https://doi.org/10.1093/ajh/hpaa149

53. Song SL, Hays SB, Panton CE, Mylona EK, Kalligeros M, Shehadeh F (2020) Statin use is associated with decreased risk of invasive mechanical ventilation in COVID-19 patients: a preliminary study. Pathogens 9:759

54. Daniels LB, Sitapati AM, Zhang J, Zou J, Bui QM, Ren J (2020) Relation of statin use prior to admission to severity and recovery among COVID-19 inpatients. Am J Cardiol 136:149-155

55. Krishnan S, Patel K, Desai R, Sule A, Paik P, Miller A (2020) Clinical comorbidities, characteristics, and outcomes of mechanically ventilated patients in the State of Michigan with SARSCoV-2 pneumonia. J Clin Anesth 67:110005. https://doi.org/10. 1016/j.jclinane.2020.110005

56. Rodriguez-Nava G, Trelles-Garcia DP, Yanez-Bello MA, Chung CW, Trelles-Garcia VP, Friedman HJ (2020) Atorvastatin associated with decreased hazard for death in COVID-19 patients admitted to an ICU: a retrospective cohort study. Crit Care 24:429

57. Rossi R, Talarico M, Coppi F, Boriani G (2020) Protective role of statins in COVID 19 patients: importance of pharmacokinetic characteristics rather than intensity of action. Intern Emerg Med 15:1573-1576

58. Strandberg TE, Kivimäki M (2021) Increased mortality risk associated with statins in the CORONADO study. Diabetes Metab 17:101250. https://doi.org/10.1016/j.diabet.2021.101250

59. Scheen AJ (2020) Statins and clinical outcomes with COVID-19: meta-analyses of observational studies. Diabetes Metab. https:// doi.org/10.1016/j.diabet.2020.07.101220

60. De Spiegeleer A, Bronselaer A, Teo JT et al (2020) The effects of ARBs, ACEIs and statins on clinical outcomes of COVID-19 infection among nursing home residents. J Am Med Dir Assoc 21:909

61. Schmidt NM, Wing PAC, McKeating JA, Maini MK (2020) Cholesterol-modifying drugs in COVID-19. Oxf Open Immunol 1(1):iqaa001. https://doi.org/10.1093/oxfimm/iqaa001 
62. Kashour T, Halwani R, Arabi YM et al (2021) Statins as an adjunctive therapy for COVID-19: the biological and clinical plausibility. Immunopharmacol Immunotoxicol 43:37-50. https://doi.org/10.1080/08923973.2020.1863984 (Epub 2021 Jan 6)

63. Luotola K, Jyväkorpi S, Urtamo A, Pitkälä KH, Kivimäki M, Strandberg TE (2020) Statin treatment, phenotypic frailty and mortality among community-dwelling octogenarian men: the HBS cohort. Age Ageing 49:258-263

64. Rea F, Mancia G, Corrao G (2020) Statin treatment reduces the risk of death among elderly frail patients: evidence from a large population-based cohort. Eur J Prev Cardiol. https://doi.org/10. 1093/eurjpc/zwaa126

65. Bianconi V, Violi F, Fallarino F, Pignatelli P, Sahebkar A, Pirro M (2020) Is acetylsalicylic acid a safe and potentially useful choice for adult patients with COVID-19? Drugs 80:1383-1396

66. Gurbel PA, Bliden KP, Schrör K (2020) Can an old ally defeat a new enemy? Circulation 142:315-317

67. Chow JH, Khanna AK, Kethireddy S et al (2020) Aspirin use is associated with decreased mechanical ventilation, ICU admission, and in-hospital mortality in hospitalized patients with COVID-19. Anesth Analg. https://doi.org/10.1213/ANE.00000 00000005292

68. Meizlish ML, Goshua G, Liu Y et al (2021) Intermediate-dose anticoagulation, aspirin, and in-hospital mortality in COVID19: a propensity score-matched analysis. Am J Hematol. https://doi.org/10.1002/ajh.26102

69. Salah HM, Mehta JL (2021) Meta-analysis of the effect of aspirin on mortality in COVID-19. Am J Cardiol S00029149(21):00003-00005. https://doi.org/10.1016/j.amjcard. 2020.12.073

70. Tsantes AE, Frantzeskaki F, Tsantes AG et al (2020) The haemostatic profile in critically ill COVID-19 patients receiving therapeutic anticoagulant therapy: an observational study. Medicine (Baltimore) 99:e23365

71. Jiménez D, García-Sanchez A, Rali P et al (2020) Incidence of VTE and bleeding among hospitalized patients with Coronavirus disease 2019: a systematic review and meta-analysis. Chest S0012-3692(20):35146-35151. https://doi.org/10.1016/j.chest. 2020.11.005 (Epub ahead of print)

72. Malas MB, Naazie IN, Elsayed N, Mathlouthi A, Marmor R, Clay B (2020) Thromboembolism risk of Covid-19 is high and associated with a higher risk of mortality: a systematic review and meta-analysis. EClinicalMedicine 29-30:100639

73. Vidali S, Morosetti D, Cossu E et al (2020) D-dimer as an indicator of prognosis in SARS-CoV-2 infection: a systematic review. ERJ Open Res 6(2):00260-02020. https://doi.org/10. 1183/23120541.00260-2020

74. Bikdeli B, Madhavan MV, Jimenez D, et al; Global COVID19 Thrombosis Collaborative Group (2020) COVID-19 and thrombotic or thromboembolic disease: implications for prevention, antithrombotic therapy, and follow-up: JACC Stateof-the-Art Review. J Am Coll Cardiol 75:2950-2973. https:// doi.org/10.1016/j.jacc.2020.04.031

75. Spyropoulos AC, Levy JH, Ageno W et al (2020) Clinical guidance on the diagnosis, prevention, and treatment of venous thromboembolism in hospitalized patients with COVID-19. J Thromb Haemost 18:1859-1865. https://doi.org/10.1111/jth. 14929

76. Moores LK, Tritschler T, Brosnahan S et al (2020) Prevention, diagnosis, and treatment of VTE in patients with coronavirus disease 2019: CHEST guideline and expert panel report. Chest 158:1143-1163. https://doi.org/10.1016/j.chest.2020.05.559

77. Testa S, Paoletti O, Giorgi-Pierfranceschi M, Pan A (2020) Switch from oral anticoagulants to parenteral heparin in
SARS-CoV-2 hospitalized patients. Intern Emerg Med. https:// doi.org/10.1007/s11739-020-02331-1

78. Kamel AM, Sobhy M, Magdy N, Sabry N, Farid S (2020) Anticoagulation outcomes in hospitalized Covid-19 patients: a systematic review and meta-analysis of case-control and cohort studies. Rev Med Virol 6:e2180. https://doi.org/10.1002/rmv. 2180

79. Wijaya I, Andhika R, Huang I (2020) The use of therapeuticdose anticoagulation and its effect on mortality in patients with COVID-19: a systematic review. Clin Appl Thromb Hemost. https://doi.org/10.1177/1076029620960797

80. Sridharan GK, Vegunta R, Rokkam VRP et al (2020) Venous thromboembolism in hospitalized COVID-19 patients. Am J Ther 27:e599-e610

81. Nadkarni GN, Lala A, Bagiella E et al (2020) Anticoagulation, bleeding, mortality, and pathology in hospitalized patients with COVID-19. J Am Coll Cardiol 76:1815-1826

82. Rossi R, Coppi F, Talarico M, Boriani G (2020) Protective role of chronic treatment with direct oral anticoagulants in elderly patients affected by interstitial pneumonia in COVID-19 era. Eur J Intern Med 77:158-160

83. Coppola A, Lombardi M, Tassoni MI et al (2020) COVID19, thromboembolic risk and thromboprophylaxis: learning lessons from the bedside, awaiting evidence. Blood Transfus 18:226-229. https://doi.org/10.2450/2020.0113-20

84. Hippensteel JA, LaRiviere WB, Colbert JF, Langouët-Astrié CJ, Schmidt EP (2020) Heparin as a therapy for COVID-19: current evidence and future possibilities. Am J Physiol Lung Cell Mol Physiol 319:L211-L217. https://doi.org/10.1152/ ajplung.00199.2020

85. Talasaz AH, Sadeghipour P, Kakavand H et al (2021) Antithrombotic therapy in COVID-19: systematic summary of ongoing or completed randomized trials. medRxiv. https:// doi.org/10.1101/2021.01.04.21249227

86. Cheruiyot I, Sehmi P, Ominde B et al (2019) Intracranial hemorrhage in coronavirus disease 2019 (COVID-19) patients. Neurol Sci. https://doi.org/10.1007/s10072-020-04870-z

87. Yan F, Huang F, Xu J et al (2020) Antihypertensive drugs are associated with reduced fatal outcomes and improved clinical characteristics in elderly COVID-19 patients. Cell Discov 6(1):77. https://doi.org/10.1038/s41421-020-00221-6

88. An J, Wei R, Zhou H et al (2020) Angiotensin-converting enzyme inhibitors or angiotensin receptor blockers use and COVID-19 infection among 824,650 patients with hypertension from a US integrated healthcare system. J Am Heart Assoc 14:e017773. https://doi.org/10.1161/JAHA.120.019669

89. Barbieri A, Robinson N, Palma G, Maurea N, Desiderio V, Botti G (2020) Can beta-2-adrenergic pathway be a new target to combat Sars-Cov-2 hyperinflammatory syndrome?-lessons learned from cancer. Front Immunol 30(11):588724. https:// doi.org/10.3389/fimmu.2020.588724

90. Vasanthakumar N (2020) Beta-adrenergic blockers as a potential treatment for COVID-19 patients. BioEssays 42(11):e2000094. https://doi.org/10.1002/bies.202000094

91. Varma N, Marrouche NF, Aguinaga L et al (2021) HRS/ EHRA/APHRS/LAHRS/ACC/AHA worldwide practice update for telehealth and arrhythmia monitoring during and after a pandemic: developed in partnership with and endorsed by the American college of cardiology (ACC), the American heart association (AHA), the Asia pacific heart rhythm society (APHRS), the European heart rhythm association (EHRA), the heart rhythm society (HRS), and the Latin American heart rhythm society (LAHRS). EP Europace. https://doi.org/10. 1093/europace/euaa187 
92. Barton AK, McGowan M, Smyth A, Wright GA, Gardner RS (2020) Classification and choice of antiarrhythmic therapies. Prescriber 31:11-17

93. Navarese EP, Musci RL, Frediani L, Gurbel PA (2020) Ion channel inhibition against COVID-19: a novel target for clinical investigation. Cardiol J 27:421-424

94. Zhou Y, Frey TK, Yang JJ (2009) Viral calciomics: Interplays between $\mathrm{Ca} 2+$ and virus. Cell Calcium 46:1-17

95. Chen X, Cao R, Zhong W (2019) Host calcium channels and pumps in viral infections. Cells 9(1):94. https://doi.org/10. 3390/cells901009

96. Israel A, Schaffer A, Cicurel A et al (2020) Large population study identifies drugs associated with reduced COVID-19 severity. Medrivx. https://doi.org/10.1101/2020.10.13.20211 953

97. Singh S, Florez H (2020) Bioinformatic study to discover natural molecules with activity against COVID-19 [version 1; peer review: 2 approved]. F1000Research 9:1203. https://doi.org/10. 12688/f1000research.26731.1

98. Sanchis-Gomar FA-O, Lavie CJ, Morin DP, Perez-Quilis C, Laukkanen JA, Perez MV (2020) Amiodarone in the COVID19 Era: Treatment for symptomatic patients only, or drug to prevent infection? (1179-187X (Electronic)). Am J Cardiovasc Drugs 1-6. https://doi.org/10.1007/s40256-020-00429-7

99. Patel C, Yan GX, Kowey PR (2009) Dronedarone Circulation 120:636-644

100. Cho J, Lee YJ, Kim JH, et al. Antiviral activity of digoxin and ouabain against SARS-CoV-2 infection and its implication for COVID-19. Research Square (Preprint) 100. https://doi.org/10. 21203/rs.3.rs-34731/v1

101. Manolis AS, Manolis AA, Manolis TA, Apostolopoulos EJ, Papatheou D, Melita H (2020) COVID-19 infection and cardiac arrhythmias. Trends Cardiovasc Med 30:451-460

102. Dan G-A, Martinez-Rubio A, Agewall S et al (2018) Antiarrhythmic drugs-clinical use and clinical decision making: a consensus document from the European heart rhythm association (EHRA) and European society of cardiology (ESC) working group on cardiovascular pharmacology, endorsed by the heart rhythm society (HRS), Asia-Pacific heart rhythm society (APHRS) and international society of cardiovascular pharmacotherapy (ISCP). EP Europace 20:731-732

103. Vitiello A, Ferrara F (2020) Antidiabetes agents against SarsCov-2 infection. SN Compr Clin Med. https://doi.org/10.1007/ s42399-020-00608-2

104. Singh AK, Gupta R, Ghosh A, Misra A (2020) Diabetes in COVID-19: prevalence, pathophysiology, prognosis and practical considerations. Diabetes Metab Syndr 14:303-310. https:// doi.org/10.1016/j.dsx.2020.04.004

105. Bouhanick B, Cracowski JL, Faillie JL; French Society of Pharmacology, Therapeutics (SFPT) (2020) Diabetes and COVID-19. Therapie 75:327-333. https://doi.org/10.1016/j.therap.2020.05. 006

106. Bornstein SR, Rubino F, Khunti K et al (2020) Practical recommendations for the management of diabetes in patients with COVID-19. Lancet Diabetes Endocrinol 8:546-550. https://doi. org/10.1016/S2213-8587(20)30152-2

107. Chen Y, Yang D, Cheng B et al (2020) Clinical characteristics and outcomes of patients with diabetes and COVID-19 in association with glucose-lowering medication. Diabetes Care 43:1399-1407. https://doi.org/10.2337/dc20-0660

108. Cariou B, Hadjadj S, Wargny M, et al.; CORONADO investigators (2020) Phenotypic characteristics and prognosis of inpatients with COVID-19 and diabetes: the CORONADO study. Diabetologia 63:1500-1515. https://doi.org/10.1007/s00125-020-05180x (Erratum in: Diabetologia. 2020 Jul 2)
109. Bramante C, Ingraham N, Murray T et al (2020) Observational study of metformin and risk of mortality in patients hospitalized with Covid-19. medRxiv. https://doi.org/10.1101/2020.06.19. 20135095 (Preprint)

110. Lally MA, Tsoukas P, Halladay CW, O'Neill E, Gravenstein S, Rudolph JL (2020) Metformin is associated with decreased 30 day mortality among nursing home residents infected with SARS-CoV2. J Am Med Dir Assoc S1525-8610(20):3092430925. https://doi.org/10.1016/j.jamda.2020.10.031

111. Singh AK, Singh R (2020) Is metformin ahead in the race as a repurposed host-directed therapy for patients with diabetes and COVID-19? Diabetes Res Clin Pract 165:108268. https://doi.org/ 10.1016/j.diabres.2020.108268 (Epub 2020 Jun 10)

112. Scheen AJ (2020) Metformin and COVID-19: from cellular mechanisms to reduced mortality. Diabetes Metab 46:423-426. https://doi.org/10.1016/j.diabet.2020.07.006

113. Muniangi-Muhitu H, Akalestou E, Salem V, Misra S, Oliver NS, Rutter GA (2020) Covid-19 and diabetes: a complex bidirectional relationship. Front Endocrinol (Lausanne) 11:582936. https://doi. org/10.3389/fendo.2020.582936

114. Drucker DJ (2020) Coronavirus infections and type 2 diabetesshared pathways with therapeutic implications. Endocr Rev 41(3):bnaa011. https://doi.org/10.1210/endrev/bnaa011

115. Chee YJ, Tan SK, Yeoh E (2020) Dissecting the interaction between COVID-19 and diabetes mellitus. J Diabetes Invest 2020(11):1104-1114. https://doi.org/10.1111/jdi.13326

116. Nakhleh A, Shehadeh N (2020) Interactions between antihyperglycemic drugs and the renin-angiotensin system: putative roles in COVID-19. A mini-review. Diabetes Metab Syndr 14:509512. https://doi.org/10.1016/j.dsx.2020.04.040

117. Pal R, Bhadada SK (2020) Should anti-diabetic medications be reconsidered amid COVID-19 pandemic? Diabetes Res Clin Pract 163:108146. https://doi.org/10.1016/j.diabres.2020. 108146

118. Rhee SY, Lee J, Nam H, Kyoung D-S, Kim DJ (2020) Effects of a DPP-4 inhibitor and RAS blockade on clinical outcomes of patients with diabetes and COVID-19. Diabet Metabol J 118. https://doi.org/10.4093/dmj.2020.0206

119. Strollo R, Maddaloni E, Dauriz M, Pedone C, Buzzetti R, Pozzilli P (2020) Use of DPP4 inhibitors in Italy does not correlate with diabetes prevalence among COVID-19 deaths. Diab Res Clin Pract 171:108444. https://doi.org/10.1016/j.diabres.2020.108444

120. Fadini GP, Morieri ML, Longato E et al (2020) Exposure to dipeptidyl-peptidase-4 inhibitors and COVID-19 among people with type 2 diabetes: a case-control study. Diabetes ObesityMetab 22:1946-1950. https://doi.org/10.1111/dom.14097

121. Mirabelli M, Chiefari E, Puccio L, Foti DP, Brunetti A (2020) Potential benefits and harms of novel antidiabetic drugs during COVID-19 crisis. Int J Environ Res Public Health 17(10):3664. https://doi.org/10.3390/ijerph17103664

122. Koufakis T, Metallidis S, Zebekakis P, Ajjan RA, Kotsa K (2020) Sodium-glucose cotransporter 2 inhibitors in the era of COVID19 pandemic: is the benefit to risk ratio still favorable? J Diab Sci Techn 14:745-747. https://doi.org/10.1177/1932296820932155

123. Zhu L, She ZG, Cheng X, Qin JJ, Zhang XJ, Cai J et al (2020) Association of blood glucose control and outcomes in patients with COVID-19 and pre-existing type 2 diabetes. Cell Metab 31(1068-77):e3

124. Bouillon R. Vitamin D and extraskeletal health. UpToDate Accessed on December 2020. https://www.uptodate.com/conte nts/vitamin-d-and-extraskeletal-health

125. Jolliffe DA, Camargo CA, Sluyter JD et al (2021) Vitamin D supplementation to prevent acute respiratory infections: systematic review and meta-analysis of aggregate data from randomised controlled trials. Lancet Diabetes Endocrin. https://doi.org/10. 1016/S2213-8587(21)00051-6 
126. Vimaleswaran K, Forouhi NG, Khunti K (2021) Vitamin D and covid-19. BMJ 372:n544. https://doi.org/10.1136/bmj.n544

127. Chakhtoura M, Napoli N, El Hajj FG (2020) Commentary: myths and facts on vitamin D amidst the COVID-19 pandemic. Metabolism 109:154276. https://doi.org/10.1016/j.metabol.2020.154276

128. Martineau AR, Forouhi NG (2020) Vitamin D for COVID-19: a case to answer? Lancet Diabetes Endocrin 8:735-736

129. Bergman P (2020) The link between vitamin D and COVID-19: distinguishing facts from fiction. J Intern Med. https://doi.org/ 10.1111/joim. 13158

130. Ali N (2020) Role of vitamin D in preventing of COVID-19 infection, progression and severity. J Infect Public Health 13:1373-1380

131. Arboleda JF, Urcuqui-Inchima S (2020) Vitamin D supplementation: a potential approach for coronavirus/COVID-19 therapeutics? Front Immun 11:1523

132. Ma H, Zhou T, Heianza Y, Qi L (2021) Habitual use of vitamin D supplements and risk of coronavirus disease 2019 (COVID-19) infection: a prospective study in UK Biobank. Am J Clin Nutr. https://doi.org/10.1093/ajen/nqaa381

133. Entrenas Castillo M, Entrenas Costa LM, Vaquero Barrios JM et al (2020) Effect of calcifediol treatment and best available therapy versus best available therapy on intensive care unit admission and mortality among patients hospitalized for COVID-19: a pilot randomized clinical study. J Steroid Biochem Mol Biol 203:105751. https://doi.org/10.1016/j.jsbmb.2020.105751.pmid: 32871238

134. Rastogi A, Bhansali A, Khare N et al (2020) Short term, highdose vitamin D supplementation for COVID-19 disease: a randomised, placebo-controlled, study (SHADE study). Postgrad Med J. https://doi.org/10.1136/postgradmedj-2020-139065

135. Murai IH, Fernandes AL, Sales LP et al (2021) Effect of a single high dose of vitamin D3 on hospital length of stay in patients with moderate to severe covid-19: a randomized clinical trial. JAMA. https://doi.org/10.1001/jama.2020.26848

136. Annweiler $\mathrm{C}$, Beaudenon $\mathrm{M}$, Gautier J, et al. COVIT-TRIAL study group (2020) COvid-19 and high-dose VITamin D supplementation TRIAL in high-risk older patients (COVIT-TRIAL): study protocol for a randomized controlled trial. Trials 21:1031. https://doi.org/10.1186/s13063-020-04928-5

137. Quesada-Gomez JM, Entrenas-Castillo M, Bouillon R (2020) Vitamin D receptor stimulation to reduce acute respiratory distress syndrome (ARDS) in patients with coronavirus SARSCoV-2 infections: revised Ms SBMB 2020_166. J Steroid Biochem Mol Biol 202:105719
138. Lips P, Cashman KD, Lamberg-Allardt C et al (2019) Current vitamin D status in European and Middle East countries and strategies to prevent vitamin D deficiency: a position statement of the European calcified tissue society. Eur J Endocrinol 180:P23-P54

139. Fang L, Karakiulakis G, Roth M (2020) Are patients with hypertension and diabetes mellitus at increased risk for COVID-19 infection? Lancet Respir Med 8:e21

140. World Health Organization. Based on currently available information, WHO does not recommend against the use of ibuprofen. Geneva: WHO; 2020. Available from: https://twitter.com/WHO/ status/1240409217997189128 [Accessed 22 April 2020].

141. Lund LC, Kristensen KB, Reilev M et al (2020) Adverse outcomes and mortality in users of non-steroidal anti-inflammatory drugs who tested positive for SARS-CoV-2: a Danish nationwide cohort study. PLoS Med 17(9):e1003308. https://doi.org/ 10.1371/journal.pmed.1003308

142. Vaja R, Kai Chan JS, Ferreira P et al (2020) The COVID-19 ibuprofen controversy: a systematic review of NSAIDs in adult acute lower respiratory tract infections. Br J Clin Pharmacol. https://doi.org/10.1111/bcp.14514

143. Ioannou P (2020) Re: Non-steroidal anti-inflammatory drugs and Covid-19; an ambiguous correlation. BMJ 368:m1185

144. Rothstein R, Leibowitz JS, Benjamin S (2020) Re: Non-steroidal anti-inflammatory drugs and Covid-19. BMJ 368:m1185

145. Kaul S, Gupta M, Bandyopadhyay D et al (2020) Gout pharmacotherapy in cardiovascular diseases: a review of utility and outcomes. Am J Cardiovasc Drugs 28:1-14. https://doi.org/10. 1007/s40256-020-00459-1

146. Hariyanto TI, Halim DA, Jodhinata C, Yanto TA, Kurniawan A (2021) Colchicine treatment can improve outcomes of coronavirus disease 2019 (COVID-19): a systematic review and metaanalysis. Clin Exp Pharmacol Physiol. https://doi.org/10.1111/ 1440-1681.13488

147. Tardif JC, Bouabdallaoui N, L'Allier PL, et al; for the COLCORONA Investigators (2021) Efficacy of colchicine in nonhospitalized patients with COVID-19. medRxiv. https://doi.org/ $10.1101 / 2021.01 .26 .21250494$

Publisher's Note Springer Nature remains neutral with regard to jurisdictional claims in published maps and institutional affiliations. 